\title{
COVID-19 en Ecuador: luto en el periodismo y zozobra informativa
}

\author{
COVID-19 in Ecuador: mourning in journalism and \\ information anxiety
}
COVID-19 no Equador: luto no jornalismo e tragédia informativa

\section{Ma. Isabel Punín* , Gabriela Sánchez Carrión** , Patricio Barrazueta***}

\begin{abstract}
RESUMEN
Esta investigación de carácter descriptivo y cronológico, identifica las causas de muerte de 38 periodistas ecuatorianos ocurridas desde marzo hasta diciembre de 2020. Ecuador es el país latinoamericano con más trabajadores de la comunicación fallecidos, después de Perú. Las cifras no son exactas y no se ha logrado una confirmación fiable en ninguno de los países, sin embargo, los decesos evidencian la precariedad laboral, el intrusismo profesional y la desatención a las mínimas normas de seguridad para la cobertura profesional, lo que ha provocado una reacción de la sociedad civil y los gremios.
\end{abstract} Palabras clave: COVID-19, Ecuador, periodismo, muerte, salud.

\section{ABSTRACT}

This descriptive and chronological research identifies the causes Keywords: of death of 38 Ecuadorian journalists from March to December COVID-19, 2020. After Peru, Ecuador has the highest mortality rate for jourEcuador, nalists in Latin America. The figures are not accurate and it is difjournalism, death, health.

\footnotetext{
* Ecuatoriana. Doctorada en Comunicación y Periodismo por Universidad Santiago de Compostela, España. Universidad Técnica Particular de Loja (UTPL). Loja, Ecuador. mipunin@utpl.edu.ec

** Ecuatoriana. Licenciada en Comunicación Social, becaria de investigación y estudiante de la maestría en Comunicación mención Investigación y Cultura Digital de la Universidad Técnica Particular de Loja (UTPL).Loja, Ecuador. gcsanchez3@utpl.edu.ec *** Ecuatoriano. Doctorado en Comunicación y Periodismo por la Universidad Santiago de Compostela, España. Universidad Técnica Particular de Loja (UTPL). Loja, Ecuador.pbarrazueta@utpl.edu.ec
} 
ficult to obtain reliable confirmation of these deaths. However, the deaths are evidence of labor instability, professional interference and disregard for minimum safety standards for professional journalistic coverage. This has provoked a reaction among the general public and from the various unions.

\section{RESUMO}

Esta pesquisa de caráter descritivo e cronológico identifica as Palavras-chave: causas de morte de 38 jornalistas equatorianos entre março e dezembro de 2020. O Equador é o país latino-americano, depois do Peru, com o maior número de trabalhadores falecidos do setor de comunicações. Os números não são exatos e nenhuma conCOVID-19, Equador, jornalismo, morte, saúde. firmação confiável foi obtida em nenhum dos países. No entanto, as mortes evidenciam a precariedade laboral, o exercício ilegal da profissão e a negligência das mínimas normas de segurança para a cobertura profissional, o que provocou uma reação da sociedade civil e das associações profissionais. 


\section{Introducción}

Pese a los avances científicos y tecnológicos, la COVID-19 es una pandemia de carácter mundial, similar a lo ocurrido con la peste negra, que azotó a la población europea (entre 1347-1351) y la fiebre española, que afectó aproximadamente a 40 millones de personas en todo el mundo (entre 1918-1920). La diferencia con aquellos antecedentes es que en la actualidad el acceso masivo a la información está marcado por la sobreabundancia de datos, criterios alarmantes y la invasión de noticias falsas que llevan a los consumidores de noticias a la incertidumbre.

La crisis sanitaria mundial, causante del síndrome respiratorio agudo severo, producido por un virus denominado SARS-CoV-2, provocó estancamientos económicos, sociales, culturales y sanitarios a nivel global, además de un aislamiento sin precedentes en la historia de la humanidad contemporánea, pero que también refrescó la precariedad laboral en la cual se desempeñan los periodistas y los trabajadores de la comunicación, en general.

El 30 de enero del 2020, el Comité de Emergencia para el Reglamento Sanitario Internacional de la Organización Mundial de la Salud (OMS) declaró el brote del nuevo coronavirus como una emergencia de salud pública de importancia internacional. En ese momento estaban confirmados más de 7.700 casos en China (país del origen de la pandemia), más de 170 muertes y 82 casos adicionales que se confirmaron en otros países (Organización Panamericana de la Salud [OPS], 2020).

Según los datos del Centro de Ciencia e Ingeniería de Sistemas (CSSE) de la universidad Johns Hopkins (2021), con corte en mayo de 2021 existían más de 169 millones de casos en todo el mundo y más de 3 millones de muertes a causa del virus. Ecuador se ubica en el puesto 47 a nivel mundial con 423.165 casos confirmados y 20.408 muertes, esta última cifra está distribuida en 14.953 muertes confirmadas por COVID-19 y otras 5.455 muertes probables de personas que tuvieron síntomas, pero no alcanzaron a realizarse una prueba (Ministerio de Salud Pública del Ecuador, 2021).

\section{Crisis del periodismo durante la pandemia}

Esta emergencia sanitaria, ligada al periodismo, enfatizó la importancia de la información como condición de vida (Cañizález, 2020). Asu- 
mir el rol periodístico de forma responsable y cuidar de su salud a la vez, es uno de los desafíos a los que se enfrentan los profesionales del periodismo en la presente epidemia global. En varias situaciones, no cuentan con las garantías adecuadas para ejercer su labor, lo cual ha costado la vida de muchos de ellos.

Los periodistas corren riesgo de contagio durante esta pandemia, porque se exponen en gran medida cuando realizan coberturas mediáticas, las que implican el contacto con una diversidad de fuentes y circunstancias. Al respecto, la ONG Campaña Emblema de Prensa (PEC, 2020) desde principios de marzo de 2020, ha recopilado información para rendir homenaje a los periodistas "asesinados por COVID-19" en el mundo; las cifras indican que existen más de 800 fallecidos en todo el mundo, siendo Ecuador uno de los países más afectados.

Esta organización afirma que los trabajadores de la comunicación están particularmente en riesgo, su trabajo no se detiene y deben acudir a hospitales, entrevistar a funcionarios, médicos, analistas económicos y especialistas durante la emergencia, para trasladar una información eficaz a sus audiencias.

Por otra parte, el uso de plataformas informáticas de comunicación ha aumentado. El nuevo entorno tecnológico ha supuesto una verdadera revolución y los medios de comunicación se han visto afectados tanto a nivel estructural como de contenidos (López García, 2012). Los periodistas aprovechan la tecnología como una herramienta valiosa para mantener contacto con las fuentes; no obstante, no ha eximido a periodistas y operadores de cubrir información en lugares considerados como focos de infección o, al menos, de alto riesgo, tales como hospitales y oficinas gubernamentales desde donde se organizaron ruedas de prensa.

La llegada de la Internet obligó al periodista tradicional a una forma diametralmente distinta de hacer periodismo (López y Mellado, 2006) una mutación que está siendo acelerada por la crisis sanitaria. Los medios no pararon de cumplir su labor pese al inminente riesgo de contagio, mientras que la ciudadanía-audiencia por su lado, volvió la mirada a los medios en busca de información contrastada.

Se trata de un proceso complejo, en el cual los ciudadanos buscan la calidad de los contenidos y no los medios en sí, por lo tanto, las empre- 
sas mediáticas tienen que luchar día a día por su audiencia. A la gestión de la información como tarea fundamental del periodista, se ha sumado la gestión de las audiencias, cambiantes y diversas, pero también el incremento de la desinformación (Bennett y Livingston, 2018).

La transparencia informativa de los gobiernos también ha sido foco de debate al cumplir con el rol de canales oficiales para informar respecto del avance de la pandemia en cada país. La apertura informativa en el campo de la salud se ha vuelto un bien que la ciudadanía busca y necesita (Díez-Garrido y Renedo, 2020). Sin embargo, en el caso ecuatoriano se han presentado deficiencias no solo al momento de exponer la información, sino también en cuanto a no comunicar, como se documentará más adelante.

Un estudio denominado La autopercepción de los roles profesionales de los periodistas en Ecuador - que forma parte del proyecto Cultura Periodística de Ecuador (CPE) — de Oller et al. (2015) determinó que los principales problemas de los periodistas en Ecuador se relacionan con: la falta de independencia de las redacciones de los medios, los bajos salarios y la baja formación o profesionalización (problemas que ya estaban consolidados antes de la pandemia) aspectos que han pasado factura durante la crisis sanitaria. En su gran mayoría, estos profesionales no tienen una vinculación laboral clara con los medios de comunicación, tampoco acceden al reconocimiento pleno de sus derechos laborales, situación que podría incidir de manera directa en la estadística de muertes que se analizará más adelante.

Asimismo, Gehrke et al. (2016) indican que la reputación de los periodistas en Ecuador no es particularmente buena. El 46,85\% de la población considera a estos profesionales como corruptos, y apenas un poco más, el 49,95\%, los califica de fiables. En tanto que un 51,74\% de la población considera que los medios de comunicación son corruptos y solamente el 45,35\% de la población los percibe como fiables.

Por otro lado, la crisis sanitaria mundial estimuló el aumento exponencial de las noticias falsas, dando paso a la difusión de especulaciones y teorías del origen del virus que se esparcieron a la misma velocidad que el virus se expande en todo el mundo (Pérez-Dasilva et al., 2020), provocando una segunda pandemia: la que está ligada a la desinformación. 
También permitió la vuelta de una audiencia que se creía dispersa y cada vez más alejada de los medios tradicionales. Nos referimos en líneas generales a la dieta audiovisual fragmentada, pero también a la crisis de veracidad que afrontan los medios en el mundo. "Ser audiencia y estar como audiencia, en contextos complejos y cambiantes como los actuales, densamente cargados de ficciones, es sin duda uno de los fenómenos socioculturales, comunicacionales y políticos más relevantes y desafiantes del momento" (Orozco, 2008, p. 10).

En cuanto a los trabajadores de la comunicación, en general, estos ejercen en un ecosistema saturado de noticias, marcado por la presencia de un prosumidor mediático (Toffler, 1980), que actúa en condición de periodista activo. Cada ciudadano es ahora mismo un medio de comunicación interactivo, y los medios en Ecuador siguen siendo monopólicos y centrados en las demandas del mercado.

$\mathrm{Al}$ respecto, la cadena nacional de televisión Teleamazonas (2020) informó que durante el mes de febrero se detectaron 39 noticias falsas, 10 de ellas tenían relación con el coronavirus. En marzo se registraron 74 publicaciones falsas vinculadas al COVID-19. La misma cantidad registrada en abril y en los meses siguientes, por lo que esto da cuenta de una tendencia que se mantiene como parte de un activismo digital ciudadano.

Los datos coyunturales citados nos permiten deducir que la audiencia y el público consumidor de información se enfrentan, en desigualdad de condiciones, a dos virus letales: la COVID-19 y la desinformación, también llamada infodemia, que puede poner la vida en riesgo ante la distribución de contenidos poco fiables, que incitan a las personas a la toma de decisiones sobre la base de información ambigua (Fundamedios, 2020a).

Ante este fenómeno, Estrada-Cuzcano et al. (2020) sugieren tres condiciones para identificar una información confiable y útil:

- Que el conocimiento que el emisor desee comunicar sea lo más exacto posible.

- Que el destinatario tenga conocimientos mínimos de lo que se quiere comunicar. 
- Que exista un lenguaje común entre las partes para analizar y describir el hecho o fenómeno.

Mientras tanto, a las características clásicas de la precariedad laboral del periodista, se sumaron riesgos para la salud relacionados con la pandemia, que nos tomó a todos desprevenidos. "La mayoría de las medidas de protección que los medios de comunicación han puesto en práctica han sido con frecuencia insuficientes“ (AFP, 2020).

La precariedad en tiempos de crisis, representa un periodismo de peor calidad (Gutiérrez et al., 2016): despidos intempestivos, cierre de algunos medios o bajas de sueldo son algunas de las causantes de esta precariedad que impide llevar a cabo con eficiencia el trabajo de la información.

A esta realidad mundial, en el caso ecuatoriano, se sumó el débil modelo empresarial con el que se administran los medios de comunicación. Proceso que está marcado por una endeble migración de los medios tradicionales a los entornos mediáticos digitales y una dependencia suprema de la publicidad, como fuente de recursos económicos.

Punín et al. (2014) argumentan en este sentido que la realidad de los medios digitales en Ecuador se mueve por la necesidad del emprendimiento, y una de las labores principales que deben ejercer estos medios es actualizar sus plataformas digitales para ofrecer un producto a la altura de las exigencias de su público, lo que a su vez se ve reflejado en un modelo sustentable de negocios.

Ante esta situación, se debe considerar que los medios de comunicación locales están tomando fuerza en las audiencias, puesto que la gente buscará proximidad, situaciones con las que se sientan identificadas y, particularmente en el contexto de la pandemia, estas audiencias buscarán acontecimientos que sucedan a su alrededor, esto es, ya no se centrarán solo en lo que ocurre en las grandes ciudades como Quito y Guayaquil, sino en las noticias de las que más se habla en los medios de comunicación nacional.

\section{Delimitación de la pandemia en Ecuador}

El primer caso de COVID-19 en Ecuador se difundió en los medios de comunicación el 29 de febrero del 2020 . Se trató de un caso importado 
de España: una mujer ecuatoriana que vino del país europeo el 14 de febrero del 2020, sin presentar síntomas.

El 11 de marzo del 2020, el presidente de la República Lenín Moreno declaró emergencia sanitaria en el país y suspendió los eventos masivos en todo el territorio, así como las clases presenciales en escuelas y colegios; pocos días después, las universidades también se acogieron a esta medida.

El 13 de marzo del 2020 se produjo la primera muerte en el país a causa del virus. Desde ese mismo día, el Comité de Operaciones de Emergencia Nacional (COE) empezó a emitir boletines e infografías con los datos del avance del virus a nivel general y por cada provincia del país, organizando conferencias de prensa en vivo, las que no fueron suficientes, pese a que se replicaron sistemáticamente por la mayoría de los medios de comunicación vigentes en el país.

El 17 de marzo de 2020, Ecuador inició de manera oficial el confinamiento hasta el 12 de septiembre del mismo año, fecha en la cual se puso fin al estado de excepción decretado por el presidente. Sin embargo, muchas personas fueron insensatas e incumplieron con las medidas restrictivas, pero también hubo aquellas que no tenían otro remedio que salir a exponerse para obtener un sustento diario. Esto ha provocado que el virus no se frene en el país, con la única esperanza de que se alcance a inmunizar a gran parte de la población con el plan de vacunación.

Los ecuatorianos afrontamos la crisis sin una voz oficial, autorizada y única que goce de algo de credibilidad, evidencia también de la ineficacia de las políticas de comunicación. No en vano "los Gobiernos no pueden confiarlo todo a la comunicación como tampoco todo a los hechos" (Canel, 2020, p. 1).

En Ecuador, se designó a la ministra de Gobierno de aquel entonces, María Paula Romo, como canal oficial de información en cuanto al número de contagios, reporte de fallecidos y acciones tomadas por el Estado. Por su parte, el vicepresidente también de ese entonces, Otto Sonneholzner, asumió la responsabilidad de atender las necesidades urgentes que se presentaron en todo el territorio, como entrega de productos de primera necesidad y la coordinación con todos los sectores estratégicos. Estos dos personajes consolidaron por algún tiempo el 
vacío y la ausencia de un presidente líder que está al frente de la crisis, con una gestión gubernamental caracterizada por la improvisación (Acosta, 2020).

A la par de la pandemia, el país también afronta una crisis política, principalmente por casos de corrupción durante la emergencia sanitaria. Las primeras evidencias aparecieron en mayo de 2020 con la sobrefacturación en el Instituto Ecuatoriano de Seguridad Social (IESS) por la compra de mascarillas a 12 dólares la unidad (Labarthe, 2020); la adquisición de 4.000 bolsas para cadáveres con $1.311 \%$ de sobreprecio; otra adquisición de 7.000 kits alimenticios con $40 \%$ de sobreprecio (González, 2020); y el reparto de hospitales a los distintos asambleístas del país, quienes habrían recibido cargos para amigos y conocidos en sus provincias, a cambio de sus votos en la Asamblea. Este último caso salió a la luz tras investigaciones periodísticas (Celi, 2020) y provocó la destitución inmediata de la ministra de gobierno, María Paula Romo.

Por su parte, el Ministerio de Salud Pública (MSP) informó que llegarían al país 2 millones de vacunas entre marzo y abril de 2021. Sin embargo, han existido quejas principalmente por parte de los trabajadores de la salud quienes no recibieron la vacuna en los tiempos planificados, a la vez que aparecieron otros casos de corrupción en donde se habrían vacunado personas que no pertenecían a primera línea, uno de ellos, el mismo ministro de Salud, Juan Carlos Zevallos y algunos de sus allegados. Después de este hecho, el ministro renunció a su cargo.

Estos actos de corrupción provocaron, además de los perjuicios a quienes más necesitaban ayuda durante la emergencia, una inestabilidad política entre los principales ministerios del país. Durante la emergencia, Ecuador ha tenido tres ministros de Salud, dos secretarios de Riesgos, dos ministros de Gobierno y dos vicepresidentes, lo que contribuye también a un dispendio económico.

En cuanto al ámbito de la comunicación oficial por parte del gobierno y las instituciones competentes, se presentó una confusión en la ciudadanía por la variabilidad de información. Por ejemplo, el 23 de abril del 2020, el COE Nacional emitió el reporte con corte a las 8:00 a.m. informando que había 11.183 casos positivos de COVID-19, lo cual fue retransmitido por los medios de comunicación a escala nacional e internacional. 
Mientras tanto, el nuevo ministro de Salud de ese entonces, Juan Carlos Zevallos, mediante una rueda de prensa informó que hasta el 22 de abril de 2020 se pudo concluir una brecha de pruebas que estaban estancadas. En ese mismo día, a los 11.183 casos se sumaron otros 10.977, dando un total de 22.190 casos positivos de COVID-19.

Esto produjo que varias personas se mostraran desorientadas y confundidas, porque simultáneamente se daban a conocer las dos cifras, lo que confirmaba la existencia de un subregistro de datos, pero también hacía evidente el escaso acceso a la información por posiciones personales de los propios voceros oficiales autorizados.

Un caso similar ocurrió el 6 de mayo de 2020. Hasta esa fecha se sabía que existían 31.881 casos, pero en el transcurso de la tarde se emitió un nuevo informe en el que se evidenció una disminución de las cifras a 29.420 casos $^{1}$.

La disparidad de los datos se produjo por la diversidad de fuentes. Los laboratorios autorizados por el Ministerio de Salud (hasta agosto de 2020 existían 409 laboratorios para pruebas tipo $\mathrm{PCR}^{2}$ en todas las provincias, excepto Bolívar) y una segunda fuente de los datos del Sistema de Vigilancia Epidemiológica. A esta realidad se sumó la cantidad de pruebas con resultados negativos, datos que confundieron a las autoridades, y mucho más a la población, que se mantuvo expectante de los canales oficiales, aunque los datos no fluyeran con exactitud.

Aunque suene paradójico, la abundancia de información (falsa en su mayoría) junto con la falta de información, forman parte de las grandes circunstancias que han acechado al país durante la crisis sanitaria. Un caso que es pertinente citar es el hecho de que no se hizo pública una lista de vacunados VIP que reclama la sociedad en los últimos tiempos, debido a que se presume que en aquella lista constaban

1 Esta variación de información se dio porque se identificó la existencia de registros duplicados, como se explicó en una nota técnica en el informe $\mathrm{N}^{\circ} 69$ del COE Nacional (Ministerio de Salud Pública del Ecuador, 2020).

2 Se tomó como referencia solamente a los laboratorios de pruebas PCR, porque se considera el test más fiable y el recomendado por la OMS. Consiste en una reacción en cadena de la polimerasa con transcriptasa inversa. En tiempo real muestra el nivel de fluorescencia, pudiendo confirmar en un $90 \%$ de confiabilidad vírica, la infección vigente en el paciente (Salazar et al., 2020). 
personas a las que aún no les correspondía recibir la dosis y lo hicieron gracias a su relación con el gobierno, o bien, con funcionarios en altos cargos del sector público, mientras que el personal de primera línea aún no se había inoculado (Rosero, 2021).

La situación actual de la pandemia en Ecuador en cuanto a los datos es imprecisa, porque no se conoce una verdadera dimensión de la pandemia y no se realizan suficientes pruebas de diagnóstico en comparación con otros países, lo que afecta la toma de decisiones estratégicas para frenar el virus en el país. Sendos reportajes de Blanca Moncada, Susana Morán o Matías Zibell, entre otros, dan cuenta de la cruda realidad de Ecuador.

\section{Metodología}

Ecuador es el segundo país latinoamericano, después de Perú, con más trabajadores de la comunicación fallecidos. Esta cifra motivó la realización de una investigación de carácter descriptivo y cronológico, que busca identificar las causas de muerte de 38 periodistas fallecidos durante la emergencia sanitaria en el país, sin dejar de lado el análisis e interpretación (Taylor y Bogdan, 1986) de los datos propios de la coyuntura relacionada con el periodismo sensacionalista.

Una de las fuentes principales para este estudio fue el último Registro Público de Medios realizado por el Consejo de Información y Comunicación del Ecuador (Cordicom, 2019). Según esta fuente, existen 1.187 medios de comunicación registrados, de los cuales 898 medios han remitido información respecto de sus trabajadores, cuyos datos indican que 7.806 personas trabajan en actividades relacionadas con la comunicación.

El presente artículo investigó la precariedad laboral del sector y su relación con la pandemia tomando en consideración las condiciones en las que se producen las muertes, para lo cual se diseñó un formulario de preguntas abiertas, que fue aplicado a los siguientes expertos descritos en la Tabla 1. 
Tabla 1

Expertos analizan la situación del periodista en Ecuador

\begin{tabular}{ll}
\hline Experto entrevistado & Trayectoria \\
\hline Blanca Moncada & $\begin{array}{l}\text { Periodista profesional. Reportera de diario Expreso } \\
\text { (Guayaquil). Responsable de la cobertura de la } \\
\text { pandemia en esa ciudad. }\end{array}$ \\
\hline Lise Josefsen Hermann & $\begin{array}{l}\text { Periodista internacional. Especializada en tema } \\
\text { sociales en Latinoamérica. }\end{array}$ \\
\hline Matías Zibell & $\begin{array}{l}\text { Profesor universitario y corresponsal en Ecuador } \\
\text { para la BBC. }\end{array}$ \\
\hline Martín Pallares & $\begin{array}{l}\text { Periodista ecuatoriano. Cofundador del portal } \\
\text { digital 4Pelagatos. }\end{array}$ \\
\hline Andrea Samaniego & Reportera de noticias en Teleamazonas (Quito). \\
\hline David Díaz & Documentalista y fotógrafo. \\
\hline
\end{tabular}

Asimismo, el artículo analiza el rol de los medios de comunicación frente a la crisis y las acciones de los principales gremios vinculados con el ejercicio profesional.

El rastreo digital en relación con los periodistas fallecidos por causas vinculadas con la pandemia inició el 29 de febrero del 2020, fecha en la cual el Estado ecuatoriano reconoció la presencia del virus. El periodo de seguimiento concluyó en diciembre de 2020. Se registró un total de 38 periodistas muertos. Para el levantamiento de información, se tomó en consideración, los siguientes aspectos:

1. Fecha de fallecimiento

2. Nombre del periodista fallecido

3. Edad

4. Causa de muerte

5. Ciudad

6. Cargo que ocupaba

7. Medio de comunicación al que pertenecía

\section{Resultados}

Uno de los resultados más importantes y de carácter inédito a los que llegó la investigación ha sido la visibilización del total de medios registrados y su relación con el número de periodistas fallecidos durante el periodo del estudio. Los aspectos más relevantes se presentan en la Tabla 2. 
Tabla 2

Relación de periodistas fallecidos, ciudad de residencia y número de medios de comunicación activos

\begin{tabular}{lcc}
\hline Ciudad & $\begin{array}{l}\text { Medios de } \\
\text { comunicación }\end{array}$ & Periodistas muertos \\
\hline Ambato & 41 & 4 \\
\hline Cuenca & 44 & 1 \\
\hline Daule & 7 & 1 \\
\hline Durán & 7 & 1 \\
\hline Esmeraldas & 16 & 1 \\
\hline Guayaquil & 164 & 20 \\
\hline La Troncal & 4 & 1 \\
\hline Lago Agrio & 21 & 1 \\
\hline Quevedo & 13 & 2 \\
\hline Pelileo & 6 & 1 \\
\hline Riobamba & 31 & 2 \\
\hline Santa Elena & 13 & 1 \\
\hline Se desconoce & $\mathrm{X}$ & 2 \\
\hline TOTAL & 367 & 38 \\
\hline
\end{tabular}

Fuente: Elaboración propia.

Como se observa en la Tabla 2, el foco de los decesos se encuentra en la ciudad de Guayaquil. De las 20 víctimas allí registradas, nueve fueron por COVID-19, mientras que tres tuvieron síntomas de este virus y no alcanzaron a realizarse la prueba. Otros seis fallecieron por otras enfermedades y en dos casos se desconoce la causa de muerte.

La situación en Guayaquil ha sido alarmante desde el inicio de la pandemia, la que varios medios de comunicación, incluso internacionales, calificaron de dramática. Durante los meses de marzo y abril de 2020 aparecieron cadáveres en las calles, otros casos de cuerpos embalados en hospitales, y la demora de trámites hizo que se acumularan personas fallecidas en la ciudad sin poder ser enterradas e, incluso, hubo casos en donde los familiares no recibieron los cuerpos de sus fallecidos.

Guayaquil vive una pesadilla. Vive escenas de películas de terror, de desesperación. Además de los gritos lastimeros que claman afuera de las casas de salud públicas y privadas para que cientos de personas agonizantes sean recibidas para tratarse del coronavirus. ( $E l$ Universo, 2020). 
Otras ciudades que registraron un alto número de víctimas por el coronavirus fueron Ambato y Riobamba, con dos casos cada una. En Cuenca, Lago Agrio, Pelileo y Santa Elena se registró también un caso confirmado en cada ciudad. Otras víctimas se localizaron en varias ciudades de la costa como Daule, Durán, Esmeraldas, La Troncal y Santa Elena, con un único caso cada una. Mientras que en Durán y Quevedo, se registró un caso con síntomas del coronavirus.

\section{¿Cuándo la edad cuenta?}

La literatura médica y divulgativa sostiene que las personas más susceptibles al contagio son los adultos mayores y aquellas con afecciones médicas preexistentes: asma, diabetes y enfermedades cardiacas. En consecuencia, se reportó una tasa de mortalidad $>8 \%$ en personas mayores de 70 años (Palacios et al., 2020).

La vulnerabilidad en este grupo etario se debe a sus reservas físicas y psíquicas, puesto que son menores a las de un adulto sano, así como también a las modificaciones en el sistema inmunológico y fisiológico, que naturalmente se produce en los adultos mayores.

Además, hay que tomar en cuenta que los adultos mayores presentan escasos síntomas en diversas afecciones, lo que dificulta el diagnóstico. Por lo general, en este sector de la población es frecuente el deterioro del estatus funcional basal, deshidratación, falta de apetito y somnolencia. Sin embargo, no existen reportes que asocien estos factores con la COVID-19, por lo tanto, es muy posible que los síntomas del virus sean escasos en los pacientes mayores.

Por su parte, la presión arterial de oxígeno ( $\mathrm{PaO} 2)$ normal varía de 75 a $100 \mathrm{mmHg}$ y se mantiene estable después de los 75 años en organismos sanos no fumadores; la presión arterial de dióxido de carbono (PaCo2), en cambio, varía de $35-45 \mathrm{mmHg}$ y de igual manera permanece constante con la edad.

Lo que se puede alterar en los adultos mayores son algunos parámetros pulmonares: reducción de la capacidad máxima respiratoria; pérdida de masa muscular por el envejecimiento y aumento de los depósitos de grasa que causan debilidad de la musculatura respiratoria; menor eficacia en el vaciado pulmonar, debido a la pérdida del retroceso elástico pulmonar; disminución de la capacidad de difusión del 
monóxido de carbono a partir de los 40 años, entre otros factores que comprometen el sistema respiratorio de personas de edad avanzada (Rozenek et al., 2020).

Ahora bien, presentada esta caracterización, resulta de interés consignar que la mayoría de los periodistas fallecidos en el periodo de estudio, fueron personas mayores de 40 años, pertenecientes al grupo vulnerable de la población en el contexto de la pandemia. La mayoría de ellos con COVID-19, y otros, con los mismos síntomas de este virus, pero no confirmados oficialmente (subregistro). Es importante destacar aquí que los medios locales digitales fueron los primeros en informar acerca del deceso de periodistas, cuando estos residían en otras ciudades que no fueron Quito y Guayaquil, cumpliéndose lo que se mencionó previamente acerca de los medios digitales locales.

Los periodistas no se diferencian del resto de la sociedad, pues son parte de la misma. Si la mortalidad es alta en el Ecuador, es obvio que la mortalidad entre los periodistas también sea alta. Muchos de los periodistas fallecidos estaban en Guayaquil donde la incidencia de muertes, en general, fue más alta que en el resto del país. En Guayaquil hubo casos de dengue y otras infecciones que coincidieron con la COVID-19 y eso aumentó la mortandad. (Martín Pallares, entrevista personal, 20 de julio de 2020).

Pese a que el trabajo en la calle, por su propia naturaleza, no contempla la aglomeración, significa de por sí un mayor riesgo al no acatar la normativa de aislamiento necesaria para evitar el contagio. Esta situación se hizo muchísimo más grave para los periodistas, quienes debieron acudir a centros de salud, lugares públicos de concentración y oficinas de las autoridades emisoras de información a cumplir con su deber profesional sin contar con el equipo de bioseguridad, una negligencia que también afectó al sector de la salud.

$\mathrm{Al}$ respecto, se evidenció que las empresas de información incumplieron parcialmente lo dispuesto en la Ley Orgánica de Comunicación (Asamblea Nacional del Ecuador, 2013) artículo 44, inciso segundo: "Ser provistos por sus empleadores de los recursos económicos, técnicos y materiales suficientes para el adecuado ejercicio de su profesión y de las tareas periodísticas que les encargan tanto en la ciudad, donde habitualmente trabajan, o fuera de ella". Dicho incumplimiento 
quedó en evidencia por los reportes y denuncias que activaron los mismos periodistas en las redes sociales, aunque no tuvieron respuesta por parte de los organismos de control.

De este modo, los periodistas se autoconvocaron casi un mes después de que se declaró la cuarentena, para exigir al Gobierno Nacional mejores condiciones de trabajo, que se comprometiera a preservar la salud y la vida, que respetara los Derechos Humanos y garantizara el ejercicio periodístico como parte de una obligación democrática (Fundamedios, 2020b). En este comunicado firmaron medios y organizaciones como Chicas Poderosas Ecuador ${ }^{3}$, medio digital $G K^{4}$, revista digital La Barra Espaciadora ${ }^{5}$, Red de Investigadores de Comunicación del Ecuador, entre otros.

Lo anterior demuestra la importancia de que los gobiernos, las empresas informativas, las instituciones y toda organización que cuente con trabajadores de la comunicación, garantice todos los implementos de bioseguridad a sus trabajadores en general, para evitar el contagio durante la pandemia, puesto que lo primero y lo fundamental es la salud de los trabajadores, aunque también hay que comprender que la sociedad en general, no estaba preparada para enfrentar una situación de esta magnitud.

En el caso del periodismo, es inédito enfrentarse a un enemigo invisible que afecta a todo el planeta. He leído a corresponsales de guerra indicando que, por primera vez, no se pueden acercar a entrevistar a las víctimas y que, también por primera vez, en esta ocasión ellos eran tan vulnerables como sus entrevistados. (Matías Zibell, entrevista personal, 13 de mayo de 2020).

3 Es una organización cuyo objetivo es promover el liderazgo femenino y la igualdad de género en los medios de comunicación. https://chicaspoderosas.org/la-organizacion/

4 Se trata de un medio nativo digital independiente con un modelo de pago por donación y suscripciones.

5 Es una revista digital de carácter colaborativo e independiente. 
Tabla 3

Edad de los periodistas fallecidos

\begin{tabular}{lc}
\hline Promedio de edad & 61,3 \\
\hline Edad mínima & 39 \\
\hline Edad máxima & 89 \\
\hline Moda & 73 \\
\hline
\end{tabular}

Por otra parte, como se aprecia en la Tabla 3, la edad promedio de los periodistas fallecidos es de 61,3 años; mientras que los menores cumplieron 40 años y el de mayor edad cumplió 89 años. En el grupo estudiado no se presenta con claridad una edad que muestre mayor repercusión, pero coinciden tres casos con 73 años, con una frecuencia de tres repeticiones. Queda claro que, no obstante, que respecto de la enfermedad, no se puede afirmar qué afectó directamente a los periodistas, aun cuando es claro que la exposición al virus fue un factor de riesgo.

Tabla 4

Causas del fallecimiento

\begin{tabular}{lc}
\hline Causa de muerte & Frecuencia \\
\hline COVID-19 & 17 \\
\hline Síntomas de COVID-19 & 4 \\
\hline Otras enfermedades & 11 \\
\hline Se desconoce & 6 \\
\hline TOTAL & 38 \\
\hline
\end{tabular}

Como se aprecia en la Tabla 4, los periodistas cuya muerte se confirmó por COVID-19 llegan a 17. Se registró la muerte de otros 4 periodistas con síntomas relacionados con el virus, en tanto que las demás muertes, 17 en total, están relacionadas con enfermedades previas como diabetes, enfermedades cardiovasculares, insuficiencia renal, o causas aún desconocidas. No se descarta la posibilidad de que los decesos fueran causados por COVID-19.

\section{Reacciones múltiples: contexto internacional y nacional}

La Organización de los Estados Americanos (OEA) emitió un comunicado de prensa realizado de manera conjunta por los garantes para la libertad de expresión y la libertad de los medios de comunicación de las Naciones Unidas, la Comisión Interamericana de los Derechos Hu- 
manos y el Representante para la libertad de los Medios de Comunicación de la Organización para la Seguridad y la Cooperación en Europa. En el comunicado recalca cinco puntos importantes:

1. Que, de acuerdo con las normas de los Derechos Humanos, los gobiernos deben brindar información veraz y accesible para todos sus ciudadanos.

2. Proporcionar el acceso a Internet.

3. Proteger el trabajo de los periodistas y garantizar el acceso a la información.

4. Emitir comunicados oficiales y sólidos a través de los medios de comunicación y evitar la propagación de noticias falsas.

5. Proteger rigurosamente los derechos individuales a la privacidad, la no discriminación, protección de fuentes periodísticas y otros derechos afines (OEA, 2020).

En cuanto a las situaciones relacionadas con el acceso a la información estas no faltaron, como comenta Josefsen Hermann (entrevista personal, 9 de mayo de 2020), quien señaló que miembros de Fuerzas Armadas obligaron a suspender una grabación realizada con un dron en la población de Pascuales (Guayaquil) que pretendía evidenciar la existencia de una fosa común ${ }^{6}$. Al respecto, el acceso a la información pública en Ecuador se encuentra en el art. 91 de la Constitución de la República y que afirma textualmente lo siguiente:

Art. 91.- La acción de acceso a la información pública tendrá por objeto garantizar el acceso a ella cuando ha sido denegada expresa o tácitamente, o cuando la que se ha proporcionado no sea completa o fidedigna. Podrá ser interpuesta incluso si la negativa se sustenta en el carácter secreto, reservado, confidencial o cualquiera otra clasificación de la información. El carácter reservado de la información deberá ser declarado con anterioridad a la petición, por autoridad competente y de acuerdo con la ley.

Sin embargo, pese a lo que dice la Constitución, durante la pandemia se han evidenciado casos como la no divulgación de la lista de

6 El reportaje completo sobre la crisis que vivió Guayaquil se puede visualizar en Josefsen Hermann (2020). 
vacunados VIP, lo cual fue ratificado por el nuevo ministro de Salud, Rodolfo Farfán, quien anunció en una entrevista para la cadena televisiva Teleamazonas (2020), que se mantendría bajo estricto secreto los nombres de las personas que ya habían recibido la vacuna contra la COVID-19, así como también por el Ministerio de Salud, que ha mantenido el mismo discurso: "La información no se dará a conocer, puesto que es confidencial” (Machado, 2021).

Ante esto, el medio digital de escala nacional, La Posta, reveló una lista de personas cercanas al gobierno que habrían recibido la vacuna de forma anticipada en enero de 2021. Esto puso en aprietos al Gobierno Nacional, presionando para que se emitieran comunicados oficiales que justificaran el porqué se habría vacunado a cierto personal, lo cual generó rechazo por parte de la ciudadanía a través de los medios sociales. Además, no faltó quién aprovechó la situación y divulgó noticias falsas, usando el mismo formato de la publicación del medio digital mencionado para modificar y colocar otros nombres de vacunados VIP, que no correspondían a la investigación periodística.

Otra historia de censura sucedió el 14 de mayo del 2020, cuando se realizaba una cobertura en el centro de la ciudad de Guayaquil: una manifestación ciudadana en rechazo a las políticas municipales aplicadas por la crisis sanitaria.

Prácticamente, nos tiraron las motos encima, empujaron a una compañera y golpearon a un compañero. Luego de eso, una cobertura en la que acompañé a personal de la funeraria a retirar el cuerpo de un cadáver que llevaba 5 días en la casa. El olor era insoportable. Pensé en la familia. (Blanca Moncada, entrevista personal, 21 de mayo de 2020).

Así también, otros comunicadores han tenido experiencias sensibles durante la cobertura al tratar de acceder a la información. El 29 de marzo de 2020, un reportero del canal televisivo RTS, Carlos Julio Gurumendi, no pudo contener el llanto y demostró su emoción en una cobertura en vivo en la parroquia Chongón perteneciente a Guayaquil (Noticias Telemundo, 2020).

Para Teleamazonas, el cambio radical ha sido pasar de las grandes cámaras y microondas a depender del celular. En la cobertura la mayor dificultad fue la carga emocional de las historias de los pacientes y sus familias, sin dejar de lado las historias de corrupción: 
El acceso a la información siempre ha sido complejo, ahora también lo es. Eso es algo que no ha cambiado por más leyes que tenemos. No hay acceso a la información si las autoridades no quieren dar paso, es imposible. (Andrea Samaniego, entrevista personal, 24 de agosto de 2020).

Para el documentalista David Díaz, existió una fuerte agresión represora:

... fue sentir la falta de empatía de las autoridades hacia la gente que lo está pasando mal. Yo acompañé a las fuerzas policiales y militares en los toques de queda y sentí impotencia al ver que en los barrios periféricos había 7 o más miembros de la familia viviendo en hogares de 2x2 o 4x4 metros, y tenían que salir a la calle, los militares usaban armas no letales, pero agresivos intimidaban a las personas para que ingresen a sus hogares. (David Díaz, entrevista personal, 24 de agosto de 2020).

Aunque Díaz asumió mucho riesgo en su trabajo ${ }^{7}$, considera que la vida es suprema y va más allá de la cobertura periodística. La pandemia, dice, está logrando que los medios revisen los protocolos de seguridad:

Hay presión internacional y organismos de periodistas internacionales como Everydayprojects o Photobillofrights, que han hecho presión y han difundido protocolos para que otros medios puedan acoplar los pasos y creo que ahora la seguridad va a ser prioridad ... Los fotógrafos freelance no tenemos seguro y si algo pasa con uno de ellos nadie se responsabiliza. Tienes en mente que no puedes ir más allá y arriesgar demasiado porque ningún medio te respalda. (David Díaz, entrevista personal, 24 de agosto de 2020).

Por su parte, Fundamedios (2020c), que se dedica a la defensa y promoción del derecho a la libertad de expresión y fomentar el periodismo de calidad en el país, ha venido realizando actividades para

7 El trabajo de Díaz se puede visualizar en este link: http://www.diazarcos.com/news . Una de sus fotos emblemáticas captada durante una jornada de protesta nacional por las medidas económicas adoptadas por el gobierno de Lenín Moreno, fue publicada por The Washington Post. 
precautelar a periodistas que están realizando coberturas mediáticas durante la pandemia.

Esta entidad, en conjunto con la UNESCO y una institución de educación superior de Ecuador, impulsaron un seminario en línea en septiembre del 2020, como parte del Programa de Salud Mental Periodismo Consciente, con un profesional de la Psicología, para tratar este tema. Se explicó que los periodistas forman parte de un grupo vulnerable porque están expuestos a emociones fuertes que aumentan durante la pandemia. Además, se sugirió que se necesita apoyo social luego de exponerse a una situación que genera emociones fuertes, y se resaltó la precariedad que, a la vez, enfrenta el periodismo ecuatoriano.

Asimismo, Fundamedios (2020b) aprovechó el 3 de mayo de 2020 — día en el que se conmemora el Día Mundial de la Libertad de Prensa- para publicar una carta abierta al presidente de la República Lenín Moreno, y al presidente de la Asamblea Nacional, César Litardo. Parte de la carta expresa textualmente lo siguiente:

En el Día Mundial de la Libertad de Prensa, dirigimos esta carta abierta al presidente Lenín Moreno y César Litardo: advertimos que ante la pandemia de COVID-19 decenas de medios de comunicación en Ecuador pueden extinguirse. ¡Urgen medidas de salvaguardia! La pandemia abrió una paradoja: hay un consumo elevado de información, pero el periodismo enfrenta un presente y futuro precario. Durante las últimas semanas son comunes los despidos masivos de las redacciones e, incluso, el final de las operaciones.

Día Mundial de la Libertad de Prensa: desde la Unesco se advierte que si ante la crisis económica y de seguridad sanitaria que generó la COVID-19 no se hace algo, se asiste a un "evento de extinción de los medios". En Ecuador es así de alarmante y real ${ }^{8}$.

El gobierno de Lenin Moreno no se ha pronunciado sobre incentivos que permitan sostener la actividad periodística. ¿Es su responsabilidad? El art. 17 de la Constitución lo indica. Pero en la situación actual ni siquiera se considera a los medios como sujeto de crédito,

8 En Ecuador, el proceso de extinción mediática se centró en los medios públicos. Quedaron solamente tres medios vigentes de alcance nacional y existen más de 500 despedidos que trabajaban para los medios públicos. 
la prensa importa. ¿Qué tienen el Gobierno y la Asamblea en sus manos? La posibilidad de aliviar la situación de quienes defienden el derecho de la ciudadanía a estar informada. ¿Cómo? Exención de IVA, líneas de crédito específicas y revisión de las directrices de ejecución presupuestaria. (Fundamedios, 2020b).

Paralelamente, Ecuador cuenta con el Comité Interinstitucional para la Protección de Periodistas, creado poco después de la desaparición y asesinato en abril de 2018 de tres periodistas vinculados con diario El Comercio. La iniciativa emanó del Ministerio de Gobierno, y otras entidades vinculadas como la Secretaría General de la Presidencia y del Cordicom, pero no se han difundido acciones reales para la defensa del sector. De los seis expertos participantes de este estudio y consultados por este tema, solo dos de ellos tenían un conocimiento periférico respecto del Comité y los otros cuatro desconocían su existencia.

\section{Discusiones y conclusiones}

La crisis sanitaria mundial ha permitido una vez más que la sociedad en general pueda ser parte activa de los medios de comunicación. La labor de los medios ha sido muy compleja y no ha podido distanciarse de las noticias falsas, una tarea en la cual la precariedad laboral y el intrusismo profesional tienen un rol protagónico y merecen una investigación mucho más detallada.

El periodismo sin duda ha cambiado con el tiempo y más aún los receptores de información. Sin embargo, la esencia misma de informar permanece intacta, y quienes valoran este oficio entenderán el aporte que genera en hechos de crisis. "El periodismo permite que una sociedad permanezca unida, que no reaccione desde lo emocional, sobre todo en contextos de crisis en que la ciudadanía necesita información fidedigna" (Orihuela, 2020).

La muerte de los periodistas ecuatorianos a causa de la COVID-19 demuestra una vez más el riesgo que supone esta profesión en tiempos de crisis: guerras, protestas, desastres naturales y, recientemente, la emergencia sanitaria, convirtiéndose directamente en una víctima más de dichas situaciones. Durante el 2020 en el contexto de la pandemia, la falta de implementos de bioseguridad y la poca eficacia ad- 
ministrativa de esta crisis, entre otras variables, ha costado la vida de 38 seres humanos que se dedicaban al periodismo y a la comunicación.

Las coberturas periodísticas por la pérdida de miles de vidas a causa de la pandemia, las situaciones de extrema pobreza a las que se enfrentan las familias ecuatorianas, y otras coberturas de impacto, generan una repercusión psicológica en los periodistas, situación que merece un estudio más detallado a futuro, puesto que la salud mental es un tema que ha tenido alto relieve en estos últimos tiempos. Waisbord y Coe (2002), consideraban que para el 2020, los principales problemas estarían relacionados con la salud mental, y no se equivocaron.

Ante esta emergencia, el usuario necesita de periodistas responsables que se acerquen lo más que puedan a la verdad, pero también aquellos que enseñen a navegar por la información, una información verificada y contrastada, con el fin de no caer en la denominada infoxicación, ni en las noticias falsas.

El perfil de periodistas, sus competencias y habilidades profesionales se renuevan todos los días (López y Mellado, 2006). No obstante, la precariedad laboral ha creado nuevas rutinas de trabajo en detrimento de la calidad informativa que se sustenta en un mínimo manejo de fuentes para la elaboración de los textos, en informaciones no contrastadas, ni verificadas, en un léxico cada vez más pobre y en un uso limitado de géneros periodísticos.

Respecto de las limitantes que existen en la cobertura periodística, varios periodistas coinciden en que, entre otras cosas, no existe la debida apertura por parte de las autoridades: “También creo que la COVID-19 ha creado más distanciamiento entre autoridades y comunicadores", asegura Lise Josefsen Hermann y cada uno de los consultados tiene sus propias experiencias en relación con la censura de parte del poder de turno y desconocen acciones particulares del Gobierno para la protección el sector.

Matías Zibell, considera que "La COVID-19 acelerará determinados cambios (los tecnológicos) y profundizará otros (la flexibilidad laboral). Imagino un escenario muy darwiniano, se salvarán los que tengan mejores capacidades para adaptarse" (Matías Zibell, entrevista personal, 13 de mayo de 2020). 
En esa misma línea, Martín Pallares y Blanca Moncada consideran que este proceso está afectado por la debilidad del modelo empresarial de los medios dependientes de la publicidad. El resto está, según Blanca Moncada, en la suscripción digital, como el compromiso de los medios de entregar un producto de calidad. La crisis sanitaria también aceleró el proceso de cierre de algunos medios públicos en Ecuador (siete medios con alcance nacional aproximadamente - creados e incautados por el gobierno-), además de un despido masivo de más de 500 empleados de los medios públicos.

Todos los periodistas y expertos consultados aseguran que las coberturas estuvieron marcadas por la desatención a las mínimas normas de seguridad, esto también como parte de la precariedad laboral. En el seguimiento y registro realizado durante 11 meses se han registrado 38 muertes, la mayoría se concentra en Guayaquil, foco de la pandemia, aunque las causas de la muerte no siempre han sido identificadas con la pandemia, como lo hemos documentado en el artículo.

Durante esta época de crisis, un aspecto positivo ha sido la participación de organizaciones para combatir las noticias falsas. Una de ellas es Ecuador Chequea, que aunque fue creado en el 2016, ha tenido un impacto importante en los últimos meses al contribuir en detectar si los enunciados de las principales autoridades del país y actores de coyuntura son ciertos, si merecen contextualización, y si son insostenibles o falsos. Otra iniciativa es Ecuador Verifica, una coalición de medios de comunicación, universidades y organizaciones que combaten la desinformación y, además, promueven la alfabetización digital.

Finalmente, se puede concluir que el gobierno de Lenín Moreno no estuvo preparado para asumir una crisis sanitaria de tal magnitud. La improvisación, inseguridad y corrupción, son algunos de los factores que componen la desconfianza y el descontento de la gente, manteniéndose expectantes de lo que un nuevo gobierno pueda ofrecer para afrontar la crisis, a propósito de las elecciones presidenciales de abril del 2021.

\section{Referencias}

Acosta, A. (2020). El Coronavirus en los tiempos del Ecuador. Análisis Carolina, (23). https://www.fundacioncarolina.es/wp-content/uploads/2020/04/AC-23.-2020.pdf 
AFP. (1 de mayo de 2020). Una ONG alerta sobre las muertes por coronavirus de periodistas desde el 1 de marzo. AFP. https://bit. ly/326mXI2

Asamblea Nacional del Ecuador. (25 de junio de 2013). Ley Orgánica de Comunicación. Registro Oficial del Gobierno del Ecuador No22. http://bit.ly/366bacL

Bennett, W. L. y Livingston, S. (2018). The disinformation order: Disruptive communication and the decline of democratic institutions. European Journal of Communication, 33(2), 122139. https://doi.org/10.1177/0267323118760317

Canel, M. (31 de marzo de 2020). Comunicación en tiempo de coronavirus. El País. https://bit.ly/310LarJ

Cañizález, A. (2020). Tiempos de COVID-19. Reflexiones sobre ética, periodismo y libertad de expresión. Temas de Comunicación, (40), 103-116. https://dialnet.unirioja.es/servlet/articulo?co digo $=7552846$ \&orden $=0$ \&info $=$ link

Celi, E. (16 de junio de 2020). El reparto de hospitales: el nuevo escándalo de la actual Asamblea. Primicias. https://www. primicias.ec/noticias/politica/reparto-hospitales-escandalo-nuevo-actual-asamblea/\#

Center for Systems Science and Engineering, CSSE. (8 de marzo de 2021). COVID-19 Dashboard by the Center for Systems Science and Engineering (CSSE) at Johns Hopkins University. Johns Hopkins University. https://gisanddata.maps.arcgis.com/apps/ dashboards/bda7594740fd40299423467b48e9ecf6

Consejo de Información y Comunicación del Ecuador, Cordicom. (2019). Registro público de medios 2019 Resultado de medios. Información general. Cordicom. https://www.consejodecomunicacion.gob.ec/servicios/rpm/

Constitución de la República de Ecuador. [Const.]. Art. 91. [Título III]. Registro Oficial 449 de 20 de octubre de 2008 (Ecuador). https://www.oas.org/juridico/pdfs/mesicic4_ecu_const.pdf

Díez-Garrido, M. y Renedo, C. (2020). La transparencia institucional y mediática del coronavirus. Un análisis de los portales de datos y de los medios de comunicación digitales en Iberoamérica. Revista Latina de Comunicación Social, (78), 393-418. https://doi.org/10.4185/rlcs-2020-1482

El Universo. (31 de marzo de 2020). Cadáveres empiezan a aparecer abandonados en varias esquinas de Guayaquil. El Univer- 
so. https://www.eluniverso.com/guayaquil/2020/03/31/ nota/7800513/coronavirus-ecuador-cadaveres-calles/

Estrada-Cuzcano, A., Alfaro, K., y Saavedra, V. (2020). Disinformation y misinformation, posverdad y fake news: precisiones conceptuales, diferencias, similitudes y yuxtaposiciones. Información, Cultura y Sociedad, (42), 93-106. http://dx.doi. org/10.34096/ics.i42.7427

Fundación Andina de Observación y Estudio Social de los Medios, Fundamedios. (23 de abril de 2020a). En época de pandemia, la viralización de desinformación pone en riesgo la vida. Fundamedios. https://www.fundamedios.org.ec/infodemia-covid19-factchecking-ecuadorchequea-taller/

Fundación Andina de Observación y Estudio Social de los Medios, Fundamedios. (3 de mayo de 2020b). Ante la pandemia, decenas de medios de comunicación pueden extinguirse. Fundamedios. https://www.fundamedios.org.ec/mediosecuador-crisis-pandemia-covid19/

Fundación Andina de Observación y Estudio Social de los Medios, Fundamedios. (11 de septiembre de 2020c). El periodista debe cuidar su salud mental. Fundamedios. https://www. fundamedios.org.ec/periodista-cuidado-salud-mental/

Gehrke, M., Lizarazo, N., Noboa, P., Olmos, D., y Pieper, O. (2016). Panorama de los medios en Ecuador. Sistema informativo $y$ actores implicados. Deutsche Welle. https://docplayer. es/17755455-Media-development-studies-panorama-delos-medios-en-ecuador-sistema-informativo-y-actores-implicados.html

González, M. (5 de octubre de 2020). Primeros casos de corrupción de la emergencia llegan a fase decisiva. Primicias. https://www. primicias.ec/noticias/politica/corrupcion-emergencia-finaliza-instruccion/

Gutiérrez, J., Ruiz, M., y Cantalapiedra, M. (2016). La precariedad en el periodismo: una historia de largo recorrido. En J. P. Marfil y M. Romer (Eds.), Retos del periodismo para el ejercicio responsable y libre de la profesión (pp. 59-74). Sociedad Española de Periodística. https://dialnet.unirioja.es/servlet/libro?c odigo $=747356 \&$ orden $=0 \&$ \&info $=$ open_link_libro

Josefsen Hermann, L. (2020). La ciudad de los muertos. Espacio Angular. https://espacioangular.org/la-ciudad-de-los-muertos/ 
Labarthe, S. (2020). ¿Qué pasa en Ecuador? COVID-19, crisis sanitaria y conflictividad política. Nueva Sociedad. https://www.nuso. org/articulo/que-pasa-en-ecuador/

López García, X. (2012). La formación de los periodistas para los entornos digitales actuales. Revista de Comunicación, (11), 178-195. https://dialnet.unirioja.es/descarga/articulo/4508642.pdf

López, A. y Mellado, C. (2006). Periodistas atrapados en la Red: rutinas de trabajo y situación laboral. Estudios Sobre El Mensaje Periodístico, (12), 161-170. https://revistas.ucm.es/index.php/ ESMP/article/view/ESMP0606110161A

Machado, J. (10 de marzo de 2021). Polémica por confidencialidad de la lista de vacunados VIP en Ecuador. Primicias. https:// www.primicias.ec/noticias/sociedad/polemica-lista-vacunados-covid-ecuador/

Ministerio de Salud Pública del Ecuador. (2021a). Situación Nacional por COVID-19 Infografía N. ${ }^{\circ} 456$ con corte el 28 de mayo del 2021. [Infografía]. https://www.gestionderiesgos.gob. ec/wp-content/uploads/2021/05/INFOGRAFIA-NACIONALCOVID19-COE-NACIONAL-08h00-28052021.pdf

Ministerio de Salud Pública del Ecuador. (2020). Situación Nacional por COVID-19 Infografía N. ${ }^{\circ} 069$ con corte el 6 de mayo del 2020. [Infografía]. https://www.gestionderiesgos.gob.ec/wpcontent/uploads/2020/05/INFOGRAFIA-NACIONALCOVI19-69-COE-NACIONAL-06052020-08h00-2.pdf

Noticias Telemundo. (2 de abril de 2020). Periodista se quiebra por la situación en Ecuador | Noticias Telemundo [Archivo de Video]. YouTube. https://www.youtube.com/ watch?v=zAKxhZbwkaA

Oller, M., Chavero, P., Carrillo, J., y Cevallos, P. (2015). La autopercepción de los roles profesionales de los periodistas en Ecuador. Quórum Académico, 12(1), 155-185. https://www.redalyc. org/pdf/1990/199040067009.pdf

Organización de los Estados Americanos, OEA. (2020). COVID-19: Los gobiernos deben promover y proteger el acceso y la libre circulación de la información durante la pandemia. Expertos internacionales. OEA. http://www.oas.org/es/cidh/expresion/showarticle.asp?artID=1170\&lID $=2$

Organización Panamericana de la Salud, OPS. (20 de enero de 2020). La OMS declara que el nuevo brote de coronavirus es una 
emergencia de salud pública de importancia internacional. OPS. https://bit.ly/3chXsIP

Orihuela, J. (30 de julio de 2020). El periodista pospandemia: cuatro ideas para reinventarse profesionalmente [ponencia]. Ciclo de conferencias "Innovación de Modelos de Negocio para Medios de Comunicación”. Consejo de Regulación, Desarrollo y Promoción de la Información y Comunicación, Quito, Ecuador. https://www.consejodecomunicacion.gob.ec/innovacion-de-modelos-de-negocio-para-medios-de-comunicacion/

Orozco, G. (2008). Audiencias y pantallas en América. Comunicar, 15(30), 10-14. https://doi.org/10.3916/c30-2008-01-001

Palacios, M., Santos, E., Velásquez, M., y León, M. (2020). COVID-19, una emergencia de salud pública mundial. Revista Clínica Española, 221(1), 55-61. https://doi.org/10.1016/j. rce.2020.03.001

Pérez-Dasilva, J., Meso, K., y Mendiguren, T. (2020). Fake news y coronavirus: detección de los principales actores y tendencias a través del análisis de las conversaciones en Twitter. El Profesional de la Información, 29(3). https://doi.org/10.3145/ epi.2020.may.08

Press Emblem Campaing, PEC. (2020). At least 111 journalists have died from Coronavirus so far in 29 countries. PEC. https:// pressemblem.ch/pec-news.shtml

Punín. M. I., Martínez, A., y Rencoret, N. (2014). Medios digitales en Ecuador: perspectivas de futuro. Comunicar, 21(42), 199207. http://dx.doi.org/10.3916/C42-2014-20

Rosero, M. (9 de marzo de 2021). Ministro de Salud asegura que no se hará pública la lista de vacunados contra el COVID-19; ¿el costo de las dosis? El Comercio. https://www.elcomercio. com/actualidad/ministro-salud-lista-vacunados-covid19. html

Rozenek, M., Soengas, N., Giber, F., y Murgieri, M. (2020). COVID-19 en adultos mayores: ¿corresponde usar la misma definición de caso? Revista Argentina de Gerontología y Geriatría, 34(1), 3-6. http://www.sagg.org.ar/wp/wp-content/ uploads/2020/04/RAGG_04_2020-3-6.pdf

Salazar, L., Maldonado, F., y Cruz, J. (2020). La PCR como prueba para confirmar casos vigentes de COVID-19. Recimundo, 4(2), 
64-74. https://www.recimundo.com/index.php/es/article/ view/824

Taylor, S. y Bogdan, R. (1986). Introducción a los métodos cualitativos de investigación. Paidós.

Teleamazonas. (15 de julio de 2020). La desinformación inunda las redes sociales. Teleamazonas. https://www.teleamazonas. com/la-desinformacion-inunda-las-redes-sociales/

Toffler, A. (1980). La tercera ola. Plaza \& Janes.

Waisbord, S. y Coe, G. (2002). Comunicación, periodismo, salud y desafíos para el nuevo milenio. Razón y Palabra, (26). http:// www.razonypalabra.org.mx/anteriores/n26/swaisbord.html 